\title{
Implicações da utilização do ficus spp. na arborização do município de Santarém, Pará
}

A arborização urbana é entendida como toda cobertura de vegetação arbórea presente nas cidades, a mesma é uma grande influenciadora na qualidade de vida da população. Porém é necessário um bom planejamento e monitoramento das espécies inseridas no ambiente urbano, de modo que se tenha os benefícios esperados da arborização. $O$ objetivo do trabalho foi identificar as implicações da utilização do Ficus spp. em 4 bairros e 11 praças do município de Santarém, Pará Foi realizado um inventário total destas áreas, considerando somente os indivíduos com altura igual ou superior a 1,5m. Considerou-se uma espécie exótica por não ser de formação originária do Brasil. Foram calculadas a Frequência absoluta (FA) e Frequência relativa (FR) da espécie Ficus spp. em relação ao número total de indivíduos inventariados. Para esse estudo foram totalizados 1416 indivíduos, dentre eles, 115 são Ficus spp. no momento do levantamento, 93,91\% dos indivíduos arbóreos estavam em estado vegetativo. Em relação a sanidade da copa das espécimes encontradas, 79,13\% possui copa saudável e sem problemas. Dentre as árvores amostradas, aproximadamente $25 \%$ da amostra necessita de algum tipo de manejo, seja poda, substituição ou remoção da árvore. Essa espécie exótica não é indicada para arborização urbana, pois tem causado conflitos com calçadas, tubulações e rede elétrica, devido terem raízes agressivas e crescimento rápido.

\section{Implications of the use of ficus spp. in the range of the municipality of Santarém, Pará}

Urban arborization is understood as all cover of tree vegetation present in the cities, it is a great influence on the quality of life of the population. However, good planning and monitoring of the species in the urban environment is necessary, so that the expected benefits of afforestation can be obtained. The objective of this work was to identify the implications of using Ficus spp. in 4 districts and 11 squares of the municipality of Santarém, Pará. A total inventory of these areas was carried out, considering only individuals with height equal or superior to 1,5m. It was considered an exotic species because it was not native to Brazil. The Absolute Frequency (FA) and Relative Frequency (FR) of Ficus spp. in relation to the total number of individuals inventoried. For this study, 1416 individuals were totalized, among them, 115 are Ficus spp. at the moment of the survey, 93.91\% of the tree individuals were in a vegetative state. Regarding the sanity of the crown of the specimens found, $79.13 \%$ had healthy crown and without problems. Among the trees sampled, approximately $25 \%$ of the sample needs some type of management, be it pruning, replacement or removal of the tree. This exotic species is not indicated for urban afforestation, as it has caused conflicts with sidewalks, pipes and power lines, due to their aggressive roots and rapid growth.

Keywords: Conflicts; Exotic; Infrastructure.

Topic: Planejamento, Gestão e Políticas Públicas Ambientais

Reviewed anonymously in the process of blind peer
Received: $12 / 04 / 2019$

Approved: $27 / 05 / 2019$
Jaine Beatriz Sousa da Silva

Universidade Federal do Oeste do Pará, Brasi http://lattes.cnpq.br/0914434709092709 jainebeatrizsousadasilva11@gmail.com

\section{Pricila da Silva Lima}

Universidade Federal do Oeste do Pará, Brasil http://lattes.cnpq.br/0233912900535413 pricila.bibi.7@gmail.com

\section{Eldeane de Castro Pires}

Universidade Federal do Oeste do Pará, Brasil http://lattes.cnpq.br/4200887834787118 eldeanecastro@gmail.com

\author{
Sarah Stephanie Rebelo Traian Baumann \\ Universidade Federal do Oeste do Pará, Brasil \\ http://lattes.cnpq.br/7722661512593219 \\ sarah.engflor@gmail.com \\ Camila Amorim Santa Brígida (iv) \\ Universidade Federal do Oeste do Pará, Brasil \\ http://lattes.cnpq.br/7618034411950250 \\ http://orcid.org/0000-0003-1229-7422 \\ brigida88camila@gmail.com \\ Livia Karine Lima Rabelo \\ Universidade Federal do Oeste do Pará, Brasil \\ http://lattes.cnpq.br/2513116920954057 \\ liviarabello16@gmail.com
}

\author{
Mayra Piloni Maestri (iD) \\ Universidade Federal Rural da Amazônia, Brasil \\ http://lattes.cnpq.br/2687102042811310 \\ http://orcid.org/0000-0002-8936-952X \\ mayrapmaestri@hotmail.com \\ Marina Gabriela Cardoso de Aquino (iD) \\ Universidade Federal do Oeste do Pará, Brasil \\ http://lattes.cnpq.br/2168843028631934 \\ http://orcid.org/0000-0002-0160-0804 \\ marinaacardosoo@gmail.com
}

\section{Referencing this:}

SILVA, J. B. S.; LIMA, P. S.; PIRES, E. C.; BAUMANN, S. S. R. T.; BRÍGIDA, C. A. S.; RABELO, L. K. L.; MAESTRI, M. P.; AQUINO, M. G. C.. Implicações da utilização do ficus spp. na arborização do município de Santarém, Pará. Revista Ibero Americana de Ciências Ambientais, v.10, n.3, p.325-334, 2019. DOI: http://doi.org/10.6008/CBPC21796858.2019 .003 .0027 


\section{INTRODUÇÃO}

Arborização urbana é considerada o conjunto de vegetação, natural ou plantada, presente em áreas públicas ou privadas como os bosques, parques, praças, jardins, ruas e calçadas das cidades (GONÇALVES et al., 2003). Esta beneficia a qualidade de vida das pessoas, através da amenização da temperatura urbana, melhoria na qualidade do ar, redução da poluição sonora, equilíbrio estético, sombreamento das ruas e calçadas, além de refúgio e alimentação para fauna e população local (PAULA et al., 2015).

Contudo, a falta de planejamento pode acarretar diversos problemas relacionados à dificuldade de deslocamento para as pessoas, danos aos bens públicos e privados, como às redes elétricas, calçadas, muros, postes de sinalização e iluminação pública, danos a paisagem urbana, além de gerar acúmulo de resíduos (LIRA, 2014). Santos et al. (2011) afirmam que o planejamento adequado inicia com a realização de um inventário, que tem como alvo principal conhecer a riqueza arbórea de um local, sendo, portanto, essencial para fornecer informações sobre o porte do vegetal, necessidade de poda, tratamentos fitossanitários, substituição, eliminação e/ou plantios, com isso, determinar prioridades de intervenções e redução de custos de manejo (ROCHA et al., 2004).

Um dos principais pontos da arborização urbana é a escolha das espécies que serão utilizadas. Entre estas, encontram-se as espécies exóticas que, quando inseridas em ambientes livres de inimigos naturais, se adaptam e reproduzem rapidamente, chegando a ocupar o espaço das espécies nativas, assim, causando mudanças nos processos ecológicos naturais, podendo tornar-se dominantes após um curto período de tempo (BIONDI et al., 2013). Neste contexto, este estudo teve como objetivo analisar as implicações da utilização do Ficus spp. na arborização do município de Santarém.

\section{REVISÃO TEÓRICA}

Alguns autores explicam o alto uso de espécies exóticas na arborização urbana, justificando ser pela falta de informações sobre a flora brasileira e seu potencial de utilização no paisagismo, principalmente as espécies ameaçadas de extinção (SILVA et al., 2010). Segundo Rangel (2005), cerca de 80\% das ruas das cidades brasileiras são arborizadas com espécies exóticas, com potencial para causar danos a bens públicos como o Ficus spp.

O Ficus é um gênero de plantas laticíferas que pertencem a família Moraceae que compreende mais de 1.800 espécies conhecidas, das quais grande parte é descrita como planta medicinal utilizada para diversos fins. Uma das espécies desse gênero é a Figueira (Ficus benjamina), uma planta exótica, originária do continente asiático, perenifólia, de 10 a $15 \mathrm{~m}$ de altura, folhas simples, coreáceas, ovaladas, verdes brilhantes, frutos globosos e avermelhados quando maduros, possui uma copa frondosa produtora de sombra, além de rápido crescimento, o que torna indicada para lugares com áreas mais permeáveis e que possibilitem o desenvolvimento de suas raízes, pois as mesmas possuem um agressivo crescimento superficial e intensa rebrota (LORENZI, 2002).

Quanto a sua utilização na arborização urbana, essa espécie possui sistema radicular agressivo e 
causa diversos problemas nos mais variados tipos de pavimentos, por isso é recomendável evitar o plantio de Ficus e, para os já implantados, substituir de forma gradativa os indivíduos dos locais com pouco espaço, pois além de evitar problemas com as calçadas, contribui para o aumento da biodiversidade das árvores na cidade (PAULA et al., 2015).

\section{MATERIAIS E MÉTODOS}

\section{Área de estudo}

O estudo foi realizado na cidade de Santarém, município situado na região Oeste do Pará, entre as coordenadas geográficas $2^{\circ} 26^{\prime} 22^{\prime \prime} \mathrm{S}$ e $54^{\circ} 41^{\prime} 55^{\prime \prime} \mathrm{O}$, com uma extensão territorial de $17.898 \mathrm{~km}^{2} \mathrm{e}$, aproximadamente, 302.667 mil habitantes (IBGE, 2019). O clima dominante da região é quente e úmido, característico das florestas tropicais, com temperatura média anual variando de $25 \circ$ a $28 \circ \mathrm{C}$ e umidade relativa média do ar de 86\% (SANTARÉM, 2018).

A avaliação da ocorrência da espécie Ficus spp. concentrou-se em 4 bairros (Aparecida, Centro, Jardim Santarém e Santa Clara) e 11 praças (Barão de Santarém, das Flores, Liberdade, Matriz, Menino Jesus, Mirante, Nossa Senhora das Graças, Parque da Cidade, Pescado, Rodrigues dos Santos e São Sebastião) do município de Santarém, cuja localização estão apresentadas na figura 1.
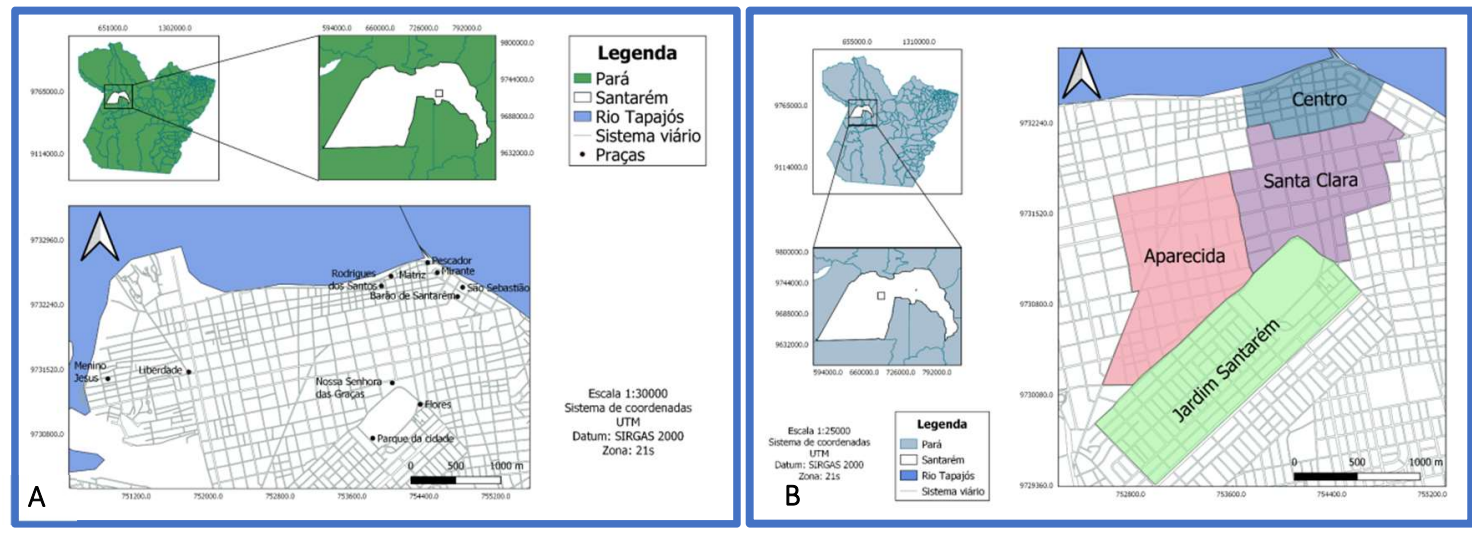

Figura 1: A. Mapa de localização dos bairros B. Praças estudadas.

\section{Coleta e análise de dados}

O censo florístico foi realizado nos meses de novembro a dezembro de 2017 nas ruas e nos meses de novembro a dezembro de 2018 nas praças, onde foram coletados os seguintes dados: nome da espécie, diâmetro a 1,3m do solo (DAP), altura (h), diâmetro de copa, fenologia, fitossanidade, necessidade de manejo (poda, remoção, substituição), contato com a fiação elétrica e origem. Foram medidos todos os indivíduos com altura $\geq 1,5 \mathrm{~m}$.

Além disso, registros fotográficos de todas as árvores inventariadas foram realizados para auxiliar na identificação botânica das espécies, além da consulta às literaturas especializadas, como Lorenzi et al. (2001) e Lorenzi (2002). Para atualização da grafia dos táxons foi utilizado o sistema Taxonomic Name Resolution Service (BOYLE et al., 2013) e o sistema de classificação APG IV foi adotado (BYNG et al., 2016). O cálculo de frequência relativa foi realizado utilizando a seguinte fórmula: 


$$
\mathrm{FR}=\frac{n^{\mathrm{o}} \text { de indivíduos }}{n^{\mathbf{0}} \text { de indivíduos total }} \times 100
$$

Quanto à origem das espécies, consideraram-se nativas aquelas originárias de formações vegetais ocorrentes no Brasil. As espécies que ocorrem em outros ecossistemas diferentes dos que aparecem em território brasileiro, foram consideradas exóticas, método adaptado de Paula et al. (2015). A tabulação e análise dos dados foram realizadas em planilhas eletrônicas.

\section{RESULTADOS}

\section{Florística}

Foram inventariados quatro bairros do município, além de 11 praças totalizando uma amostra vegetal composta de 1656 indivíduos arbóreos, na qual, 115 eram de Ficus spp., sendo 104 de Ficus benjamina e 11 de Ficus elastica. Dentre todas as espécies encontradas na arborização urbana das áreas estudadas, 6,94\% correspondem ao Ficus spp. Desta, 40,86\% estão no bairro Aparecida, 31,30\% no bairro Santa Clara, $24,34 \%$ no bairro Centro e o bairro Jardim Santarém com a menor frequência de indivíduos de Ficus spp., apenas $3,48 \%$.

\section{Fenologia}

No que trata da fenologia, no momento do levantamento (outubro, novembro e dezembro de 2017 e 2018), 93,91\% dos indivíduos arbóreos estavam em estado vegetativo, 1,74\% apresentava floração, 3,48\% estavam frutificando e $0,87 \%$ encontrava-se em período de troca de folhas.

\section{Infraestrutura}

Em relação à altura dos indivíduos amostrados, 16,52\% das árvores medem menos de 4 metros de altura, 21,74\% possuem entre 4 e 6 metros sendo classificados como árvores de pequeno porte, 44,35\% têm altura entre 6 e 8 metros e classificados como árvores de médio porte e 17,39\% medem mais de 10 metros de altura sendo estes indivíduos arbóreos de grande porte.

Das características da copa analisou-se o diâmetro, na qual 76\% possuem copa com até 7 metros, $8 \%$ tem copa entre 8 a 10 metros e 16\% possuem copa com mais de 10 metros de diâmetro. Quanto ao estado das raízes das árvores analisadas, 44,35\% têm raízes sem afloramento, 0,87\% possuía raiz sem afloramento, porém apresentava rachadura nas estruturas próximas, 25,22\% está com afloramento contido e 29,56\% apresenta afloramento grave com danos e prejuízos nas estruturas de sua proximidade.

\section{Fitossanidade}

Dentre as características analisadas durante o levantamento, observou-se o estado fitossanitário da árvore, considerando as copas, fustes e raízes e, a partir de então, classificou-se em uma escala de 0 a 3, conforme demonstra a tabela 1. 
Tabela 1: Condições de fitossanidade. FR: Frequência Relativa.

\begin{tabular}{|l|l|l|l|l|l|l|}
\hline FITOSSANIDADE & Copa & FR(\%) & Fuste & FR(\%) & Raízes & FR(\%) \\
\hline Condição & 91 & 79,13 & 86 & 74,78 & 66 & 57,39 \\
\hline 0 & 3 & 2,61 & 2 & 1,74 & 0 & 0 \\
\hline 1 & 8 & 6,96 & 22 & 19,13 & 4 & 3,48 \\
\hline 2 & 13 & 11,30 & 5 & 4,35 & 45 & 39,13 \\
\hline 3 & 13 & 13 & 45 \\
\hline
\end{tabular}

*Condição: Copa: 0 - Sem problemas; 1 - Presença de cupim; 2 - Presença de parasita; 3 - Podridão; Fuste: 0 - Sem problemas; 1 - Presença de cupim; 2 - Presença de ocos; 3 - Podridão; Raízes: 0 - Sem problemas; 1 - Raízes cortadas; 2 - Apodrecimento; 3 - Raízes estranguladas.

Em relação a sanidade da copa das árvores analisadas, 79,13\% possuem copa saudável e sem problemas. Entretanto, 11,30\% apresentam podridão em seus galhos e 9,57\% possuem cupim e/ou parasitas em sua estrutura. Das condições do fuste, a maior parte da amostra $(74,78 \%)$ possui fuste sadio e sem problemas e o restante $(25,22 \%)$ apresenta presença de cupins, ocos e/ou podridão em sua estrutura. As raízes de 57,39\% das árvores estão em boas condições, sem problemas visíveis, enquanto 3,48\% possuem algumas raízes podres e $39,13 \%$ apresentam raízes estranguladas devido à falta de espaço para seu crescimento.

\section{Manejo}

Em relação à proximidade dos indivíduos com a rede elétrica na cidade de Santarém, observou-se que $62,61 \%$ estavam em áreas com ausência de fiação ou não apresentava riscos, $12,17 \%$ apresentavam potencial risco de entrarem em contato com essa estrutura e $25,22 \%$ dos indivíduos estavam em contato com a rede elétrica.

Ao observar a inclinação dos indivíduos, foi possível notar que $94,78 \%$ das árvores possuem inclinação normal, 3,48\% demonstram uma inclinação para a rua e 1,78\% estão inclinadas para o lado de residências o que, dependendo das condições da sanidade da planta, pode oferecer riscos e necessitar de algum tipo de manejo, como mostra a figura 2.

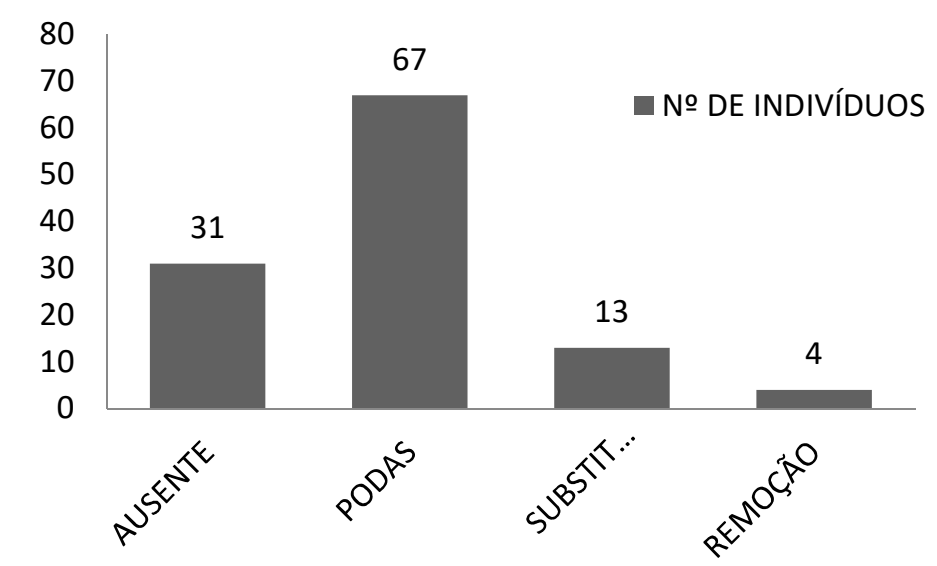

Figura 2: Número de indivíduos que necessitam algum tipo de manejo.

Dentre todos os indivíduos de Ficus spp. amostrados, $73,0 \%$ apresentam necessidade de algum tipo de manejo, sendo que grande parte destes (79,76\%) apresenta necessidade de podas, em $14,48 \%$ precisa haver a substituição dos indivíduos e 4,76\% dos indivíduos necessitam ser removidos, pois estão em local 
inadequado para plantio afetando alguma estrutura urbana.

\section{DISCUSSÃO}

\section{Florística}

Em um estudo feito por Eurich et al. (2014), sobre a arborização urbana da área central de Ponta Grossa/PR foi encontrado um total de 1238 árvores, na qual 108 são indivíduos de Ficus spp. pertencentes a 3 espécies (F. benjamina, F. variegata e F. elastica) onde a maior parte (68) são da espécie Ficus benjamina. Nota-se a semelhança de valores quanto a quantidade de indivíduos encontrados nos quatro bairros analisados em Santarém. Outro estudo feito em dois bairros de Nova Iguaçu/RJ por Rocha et al. (2004) encontraram 262 indivíduos de Ficus spp. pertencentes apenas à espécie de Ficus benjamina, onde 121 árvores estavam nas ruas e avenidas do Bairro Rancho Novo e 141 localizadas nas rodovias e avenidas do Bairro Centro.

Paula et al. (2015), ao analisarem a arborização do bairro Centro do município de Cataguases/MG, identificaram 93 indivíduos de Ficus benjamina e um de Ficus enormis. Novamente, é possível observar que a quantidade por bairro neste município equivale a um valor maior que a quantidade encontrada por bairro no município do presente estudo. Nesse contexto, é possível afirmar que apesar da grande quantidade de indivíduos dessa espécie encontrados no presente estudo, ainda é menor que em muitos municípios brasileiros.

\section{Fenologia}

Em um estudo realizado por Reys et al. (2005), na mata ciliar do rio Formoso em Mato Grosso do Sul, as espécies de Ficus spp. encontravam-se em estado vegetativo no período da coleta (outubro a dezembro), os autores apontam também que a floração ocorre em setembro e sua frutificação acontece em abril. Tal observação está de acordo com o constatado sobre a fenologia do Ficus spp. em Santarém, em relação ao estado vegetativo, porém, a floração e frutificação de poucos indivíduos arbóreos aqui encontrados nestas fases fenológicas está incompatível com o período apontado pelos autores.

\section{Infraestrutura}

O porte das árvores escolhidas para a arborização urbana está diretamente relacionado com o local de plantio, disponibilidade de espaço, proximidade de edificações e principalmente com o tipo de fiação elétrica local, apontados na tabela 2. Embora o maior exemplar de Ficus spp. amostrado possua 15 metros de altura, percebe-se que se trata de árvores ainda jovens, pois segundo Santos et al. (1997), indivíduos adultos de Ficus benjamina e Ficus elastica medem entre 20 a 35 metros de altura. Uma método muito usado para controlar a estrutura vertical dos indivíduos é a poda, entretanto, quando é feito o uso de podas drásticas para acabar com o contato entre a árvore e a rede elétrica, esta responde com uma maior quantidade de brotações que em curto espaço de tempo alcançarão novamente a fiação (VELASCO, 2003). 
Tabela 2: Porte arbóreo recomendado conforme a infraestrutura.

\begin{tabular}{|l|l|l|l|}
\hline Porte arbóreo & Largura da calçada & Tipo de Fiação & Recuo predial \\
\hline Pequeno & A partir de $2 \mathrm{~m}$ & Convencional & Presente ou ausente \\
\hline Médio & A partir de $2 \mathrm{~m}$ & Ausente, protegida ou isolada & Mínimo de 3m \\
\hline Grande & A partir de $2,5 \mathrm{~m}$ & Ausente, protegida ou isolada & Mínimo de $3 \mathrm{~m}$ \\
\hline
\end{tabular}

Quanto ao diâmetro de copa das árvores, Ficus benjamina apresenta copa consideravelmente grande, alcançando cerca de 30 metros de diâmetro, promovendo uma boa quantidade de sombra e oferecendo os benefícios esperados da arborização. Contudo, Pivetta et al. (2002) alertam para o fato que árvores com copas muito grandes interferem na fiação aérea e na passagem de veículos. As árvores dispostas nas calçadas competindo por espaço com a fiação elétrica é um dos maiores problemas da arborização das cidades (VELASCO et al., 2006). Nota-se que no meio urbano, essas árvores sofrem demasiada quantidade de podas, geralmente feitas por empresas de fornecedoras de energia elétrica assim como ocorre em Santarém. Segundo Lundgren et al. (2013), a espécie Ficus benjamina suporta muito bem as podas.

Os conflitos entre arborização e fiação elétrica são amplamente abordados em estudos científicos, onde na maioria deles, a solução indicada é o plantio de espécies de pequeno porte próximo à fiação com o objetivo de diminuir a necessidade de podas. No entanto, Gonçalves et al. (2004) alertam para o fato que embora árvores de pequeno porte possam evitar o conflito com a rede elétrica, também podem não trazer os benefícios esperados de uma boa arborização. Neste contexto, os autores aconselham que a adaptação não deva ser das árvores, mas sim da fiação elétrica, podendo ser utilizadas sob a fiação viária, desde que não sejam plantadas no alinhamento da rede e que a copa das árvores seja conduzida precocemente por meio de podas de conformação, acima dessa rede, para que não venha a conflitar com a fiação viária.

O gênero Ficus spp. possui crescimento radicular fasciculado com comportamento agressivo que frequentemente causa danos a estrutura viária, como quebrar calçadas e tubulações subterrâneas das redes de água, esgoto e até mesmo fiação elétrica. O afloramento das raízes é um dos principais problemas diagnosticado por vários autores que realizam estudos sobre arborização. Em Santarém, os resultados obtidos demonstram que aproximadamente metade da amostra total de Ficus apresenta algum tipo de afloramento. O afloramento é facilmente observado em raízes sob solo impermeabilizado, que não conseguem absorver água de forma eficiente (MARCHIORI, 2004).

Segundo Santos et al. (2001), o afloramento das raízes é devido à ausência de área livre para o crescimento do caule das árvores causando estrangulamento do mesmo, também impede a penetração de água e nutrientes, forçando ou favorecendo o afloramento das raízes assim como a quebra de tubulações subterrâneas para buscar os elementos necessários para o desenvolvimento, como ocorre com os indivíduos de Ficus spp. Em algumas cidades é utilizado tubos de concreto para realizar o direcionamento das raízes acreditando-se que isso evitará a ocorrência de afloramento porque, em teoria, as raízes cresceriam de forma pivotante (PAGLIARI et al., 2013).

\section{Fitossanidade}

Barbosa et al. (2017), ao analisarem a presença de erva-de-passarinho na arborização do Campus do 
Instituto Federal Sudeste MG, notaram que $14 \%$ da população amostrada eram Ficus benjamina com a presença deste parasita, em Santarém, o número encontrado equivale à metade deste valor, demonstrando que esta espécie não apresenta grandes problemas com parasitas.

A presença de cupins nos indivíduos de Ficus spp. é baixa, o que poderia ser explicado pelo fato de cupins não demonstrarem afinidade com algumas espécies arbóreas (DUARTE et al., 2008). Fungos de podridão geralmente não matam as árvores, entretanto, se presentes nas raízes podem mata-las, o que pode ocasionar a queda da árvore pelo vento. Segundo Albertin et al. (2005), árvores ocadas com presenças de cupins ou que apresentam podridão são mais difíceis de recuperar e podem ser erradicadas entre dois a cinco anos.

\section{Manejo}

Dentre as árvores amostradas, grande parte da amostra necessita de algum tipo de manejo, seja poda, substituição ou remoção da árvore. A poda é recomendada para reduzir os conflitos entre as árvores e os elementos urbanos, assim como proporcionar um aspecto visual agradável (ENERSUL, 2005). O contato de galhos com a rede elétrica, dependendo do tipo de fiação, pode ocasionar curto circuito ou o rompimento dos fios provocando o desligamento da rede, a queima de aparelhos e acidentes (MASCARÓ, 2002). Em Santarém, observa-se que mais da metade dos indivíduos amostrados possuem a necessidade de poda.

Entretanto, como a poda é uma agressão a esses indivíduos geralmente compromete a sanidade das árvores e descaracteriza o crescimento normal de uma dada espécie, além de resultar em custos onerosos se for necessário realiza-la com frequência (SEITZ, 2012). A substituição é indicada para árvores com problemas fitossanitários, que estejam comprometendo sua vitalidade, que sofreram sucessivas podas inadequadas ou que apresentam risco de tombamento (ENERSUL, 2005). Neste estudo, como a maioria das árvores apresentam boa fitossanidade geral, não se faz necessária uma grande quantidade deste tipo de manejo.

A remoção é indicada quando a permanência da árvore indica um risco tanto a população quanto ao patrimônio público, sem possibilidade de uso de outros métodos de correção, como no caso de árvores mortas. Um estudo realizado na cidade de Itapira/SP mostrou que $20 \%$ dos indivíduos de Ficus precisam ser removidos, enquanto em Santarém, apenas 4,76\% apresentam tal necessidade, demonstrando que neste município a necessidade deste tipo de manejo é relativamente baixa.

\section{CONCLUSÕES}

Considerando-se os aspectos avaliados da arborização de Santarém, percebe-se que a utilização de Ficus spp. na arborização viária torna-se inviável pela quantidade de danos que causa principalmente em calçadas e ruas, devido ao seu crescimento radicular agressivo. Mas, levando em conta que a arborização urbana é o conjunto de terras públicas e privadas com cobertura arbórea em uma cidade, e não somente em ruas e praças, nota-se que há inúmeros espaços adequados para o plantio de Ficus spp. que geralmente são árvores de grande porte. 


\section{REFERÊNCIAS}

ALBERTIN, R. M.; ANGELIS, R.; ANGELIS NETO, G.; ANGELIS, B. L. D.. Diagnóstico quali-quantitativo da arborização viária de Nova Esperança, Paraná, Brasil. Revista da Sociedade Brasileira de Arborização Urbana, Piracicaba, v.6, n.3, p. 128-148, 2011.

BARBOSA, J.; FRANÇA, G.. Avaliação da infestação de ervade-passarinho (Loranthaceae) no IF Sudeste MG/Campus Barbacena. In: SIMPÓSIO DE PESQUISA E INOVAÇÃO, 8. Anais. IFMG, 2017.

BIONDI, D.; MULLER, E.. Espécies arbóreas invasoras no paisagismo dos parques urbanos de Curitiba/PR. Revista Floresta, Curitiba, v.43, n.1, p.69-82, 2013.

BOYLE, B.; HOPKINS, N.; LU, Z.; GARAY, J. A. R.; MOZZHERIN, D.; REES, T.; MATASCI, N.; NARRO, M. L.; PIEL, W. H.; MCKAY, S. J.; SONYA, L.; CHRIS, F. P. R. K.; BRIAN, J. E.. The taxonomic name resolution service: an online tool for automated standardization of plant names. BMC bioinformatics, v.14, n.1, p.16, 2013.

BYNG, J. W.; CHASE, M. W.; CHRISTENHUSZ, M. J. M.; FAY, M. F.; JUDD, W. S.; MABBERLEY, D. J.; SENNIKOV, A. N.; SOLTIS, D. E.; SOLTIS, P. S.; STEVENS, P. F.; BRIGGS, B.; BROCKINGTON, S.; CHAUTEMS, A.; CLARK, J. C.; CONRAN, J.; HASTON, E.; MOLLER, M.; MOORE, M. J.; OLMSTEAD, R. G.; et al. An update of the Angiosperm Phylogeny Group classification for the orders and families of flowering plants: APG IV. Botanical Journal of the Linnean Society, v.181, n.1, p.1-20, 2016.

DUARTE, F. G.; SANTOS, G. A.; ROSADO, F. R.; DELARIVA, R. L.; SAMPAIO, A. C. F.. Cupins (Insecta: Isoptera) na arborização urbana da zona 1 de Maringá/PR. Revista em Agronegócios e Meio Ambiente, v.1, n.1, p.87-99, 2008.

ENERSUL. Empresa Energética de Mato Grosso do Sul. Guia de Arborização Urbana. Campo Grande: Enersul, 2005.

EURICH, Z. R. S.; CARNEIRO, D. C.; MALISKI,F. L.; GONÇALVES N. G. T.; CARVALHO, S. M.. Análise da arborização urbana da área central de Ponta Grossa/PR. Revista Perspectiva Geográfica, v.9, n.10, 2014.

GONÇALVES, S.; ROCHA, F. T.. Caracterização da arborização urbana do bairro de Vila Maria Baixa. Conscientia e Saúde, v.2, p.67-75, 2003.

GONÇALVES, W.; PAIVA, H. N.. Árvores para o ambiente urbano. Viçosa: Aprenda Fácil, 2004.

IBGE. Instituto Brasileiro de Geografia e Estatística. Brasil em Síntese. Brasília: IBGE, 2019.

LIRA, E. S.. Diagnóstico da arborização urbana na área central de Corumbá/MS. In: ENEPEX, ENCONTRO DE ENSINO PESQUISA E EXTENSÃO. Anais. Corumbá: UEMS, 2014.

LORENZI, H.. Árvores Brasileiras: Manual de Identificação e Cultivo de Plantas Arbóreas do Brasil. 4 ed. São Paulo: Instituto Plantarum, 2002.

LORENZI, H.; SOUZA, H. M.. Plantas ornamentais no Brasil: arbustivas, herbáceas e trepadeiras. 3 ed. São Paulo:
Instituto Plantarum, 2001.

LUNDGREN, W. J. C, ; SILVA, L. F. ; ALMEIDA, A. Q.. Influência Das Espécies Exóticas Árboreas Urbanas Na Área De Cobertura Da Cidade De Serra Talhada/PE. Revista da Sociedade Brasileira de Arborização Urbana, Piracicaba, v.8, n.3, p.96-107, 2013.

MARCHIORI, J. N. C.. Elementos de dendrologia. 2 ed. Santa Maria: UFSM, 2004

MASCARÓ, L. E.. Vegetação Urbana. Porto Alegre, 2002.

PAGLIARI, S. C.; DORIGON, E. B.. Arborização urbana: importância das espécies adequadas. Unoesc \& Ciência ACET, Joaçaba, v.4, n.2, p.139-148, 2013.

PAULA, L.; DUARTE, M. S. S.; TOSTES, R. B.; OLIVEIRA JUNIOR, P. R.; RUBACK, S. S.. Arborização urbana do bairro Centro do município de Cataguases, MG. Revista Agrogeoambiental, Pouso Alegre, v.7, n.2, p.101-112, 2015.

PIVETTA, K. F. L.; FILHO, D. F. S.. Arborização Urbana. Boletim Acadêmico. Jaboticabal: UNESP, 2002.

RANGEL, S.. A arborização urbana e o uso de espécies florestais nativas da mata atlântica. Brasília: Embrapa Documentos, 2005.

REYS, P.; GALETTI, M.; MORELATTO, P.; SABINO, E. J.. Fenologia reprodutiva e disponibilidade de frutos de espécies arbóreas em mata ciliar no Rio Formoso, Mato Grosso do Sul. Biota Neotropica, v.5, n.2, 2005.

ROCHA, R. T.; LELES, P. S. S.; NETO, S. S. O.. Arborização de vias públicas em Nova Iguaçu, RJ: O caso dos bairros Rancho Novo e Centro. Revista Árvore, Viçosa, v.28, n.4, p.599-607, 2004.

SANTARÉM. Portal da Prefeitura de Santarém. Santarém, 2019.

SANTOS, A. C. B.; SILVA, M. A. P.; SOUZA, R. K. D.. Levantamento florístico das espécies utilizadas na arborização de praças no município de Crato, CE. Caderno de Cultura e Ciência, Crato, v.10, n.1, p.13-18. 2011.

SANTOS, E.; RAMALHO, R. S.. O gênero Ficus (Moraceae) em Viçosa-MG. Revista Cerne, v.44, n.256, p.646-665, 1997.

SANTOS, N. R. Z.; TEIXEIRA, I. F.. Arborização de vias públicas: ambiente $x$ vegetação. Porto Alegre: Instituto Souza Cruz, 2001.

SEITZ, R. A.. Poda Urbana: Princípios básicos e execução. In: ENCONTRO GAÚCHO DE ARBORIZAÇÃO URBANA. Anais. Pelotas: SBAU, 1999.

SILVA, J. G.; PERELLÓ, L. F. C.. Conservação de espécies ameaçadas do Rio Grande do Sul através de seu uso no paisagismo. Revista da Sociedade Brasileira de Arborização Urbana, Piracicaba, v.5, n.4, p.1-21, 2010.

VELASCO, G. D. B.; LIMA, A. M. L.; COUTO, H. T. Z.. Análise comparativa dos custos de diferentes redes de distribuição 
de energia elétrica no contexto da arborização urbana.

Revista Árvore, Viçosa, v.30, n.4, 2006.

VELASCO, G. D. N.. Arborização viária $\mathrm{x}$ sistema de distribuição de energia elétrica: Avaliação dos custos, estudo das podas e levantamento de problemas fitotécnicos. Dissertação (Mestrado em Fitotecnia) - Escola Superior de Agricultura 'Luiz de Queiroz', Piracicaba, 2003.

A CBPC - Companhia Brasileira de Produção Científica (CNPJ: 11.221.422/0001-03) detém os direitos materiais desta publicação. Os direitos referem-se à publicação do trabalho em qualquer parte do mundo, incluindo os direitos às renovações, expansões e disseminações da contribuição, bem como outros direitos subsidiários. Todos os trabalhos publicados eletronicamente poderão posteriormente ser publicados em coletâneas impressas sob coordenação da Sustenere Publishing, da Companhia Brasileira de Produção Científica e seus parceiros autorizados. Os (as) autores (as) preservam os direitos autorais, mas não têm permissão para a publicação da contribuição em outro meio, impresso ou digital, em português ou em tradução. 